\title{
Cervical Nerve Root Compression Due to Vertebral Artery Loop Indentation: Case Report
}

\author{
Devrim Ulaş Urut
}

Biruni University Hospital, Istanbul, Turkey

\begin{abstract}
Symptoms such as pain, numbness, and loss of muscle strength may occur as a result of cervical discopathies and spondylosisassociated cervical nerve palsy symptoms. Vertebral artery loop formation is a rare vascular pathology associated with nerve root compression resulting in similar clinical symptoms. The treatment strategy may be completely different following the diagnosis. Magnetic resonance imaging of the patient who admitted to our hospital due to complaints of right-sided numbness detected vertebral artery loop causing narrowing of the neural foraminal area and C3 nerve compression. No significant pathology was found in the Doppler ultrasound (US) examination performed for the vertebral artery vasculature following the examination. Cervical disc pathologies are the main pathology in the vast majority of patients suffering from cervical region pain and numbness and loss of strength. In rare cases, keeping in mind the other pathologies that constrain neural foraminal area is useful for differential diagnosis.
\end{abstract}

Keywords: Cervical spine; radiculopathy; vascular compression; vertebral artery loop.

Please cite this article as "Urut DU. Cervical Nerve Root Compressıon Due to Vertebral Artery Loop Indentatıon: Case Report. Med Bull Sisli Etfal Hosp 2018;52(4):307-309".

$T$ he vertebral arteries arise from the subclavian artery on the ipsilateral side and enter the transversal foramina with the vertebral vein and accompanying sympathetic nerve plexuses at the $\mathrm{C} 6$ level. At the level of $\mathrm{C} 2$, they show lateral orientation, and head toward the cranial direction and passes through the vertebra foramen. At this level, they turn toward the posterior direction and course superomedially where both VAs run at the level of the foramen magnum to form the basilar artery in the posterior fossa, usually at the level of the medulla spinalis. ${ }^{[1]}$

Deformations and anatomical variations of the neural foramen affect the vital vessels and nerves during their course, leading to pathological conditions and thus clinical symptoms. ${ }^{[1,2]}$

\section{Case Report}

A 46-year-old woman who had a history of appendectomy and mass lesion excision from her right breast was admit- ted to our hospital with pain in the neck region and numbness in her right arm. Physical examination revealed pain at the cervical region and trigger points bilaterally on upper parts of the trapezius muscle on palpation. Movements of the neck were restricted in all directions, and the Spurling test on the right side was considered positive. Upper extremity muscle strength was complete, and no pathology was detected during sensory examination. Deep tendon reflexes were bilaterally normoactive. No pathological reflex was detected. The patient was referred to our clinic for cervical magnetic resonance imaging (MRI) based on the findings of the present complaints and physical examination. In the cervical MRI, vascular structures with signal void areas that obliterated right neural foramen at the level of C2-C3 articular disc, and compressed right C3 nerve root and vascular structures with curved appearance attracted our attention (Figs. 1, 2). Although signal loss consistent

Address for correspondence: Devrim Ulaş Urut, MD. Biruni Üniversite Hastanesi, İstanbul, Turkey

Phone: +90 5333160372 E-mail: dr_duurut@yahoo.com

Submitted Date: May 11, 2017 Accepted Date: May 17, 2017 Available Online Date: December 28, 2018

${ }^{\circ}$ Copyright 2018 by The Medical Bulletin of Sisli Etfal Hospital - Available online at www.sislietfaltip.org

This is an open access article under the CC BY-NC-ND license (http://creativecommons.org/licenses/by-nc/4.0/). 
with degenerative changes in cervical intervertebral articular discs was observed, any pathological finding was found on both sides occupying other neural foraminal areas. Contrast-enhanced lesion was not observed after contrast injection. Contrast-enhanced MR angiography of the cervical region revealed a significant loop formation in the distal extracranial segment of the right VA (Fig. 3). No pathological findings were found in the radius health strikes (RDUS) examination performed following MRI (Fig. 4).

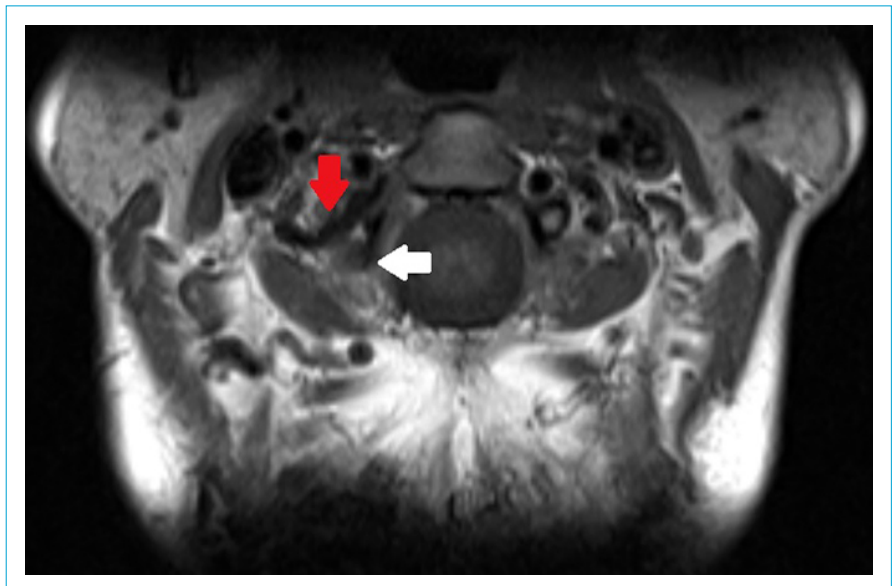

Figure 1. Vascular loop of the vertebral artery (red arrowhead) constricting right neural foramen at the level of C2-3, and compressed C3 nerve root at this level (white arrowhead).

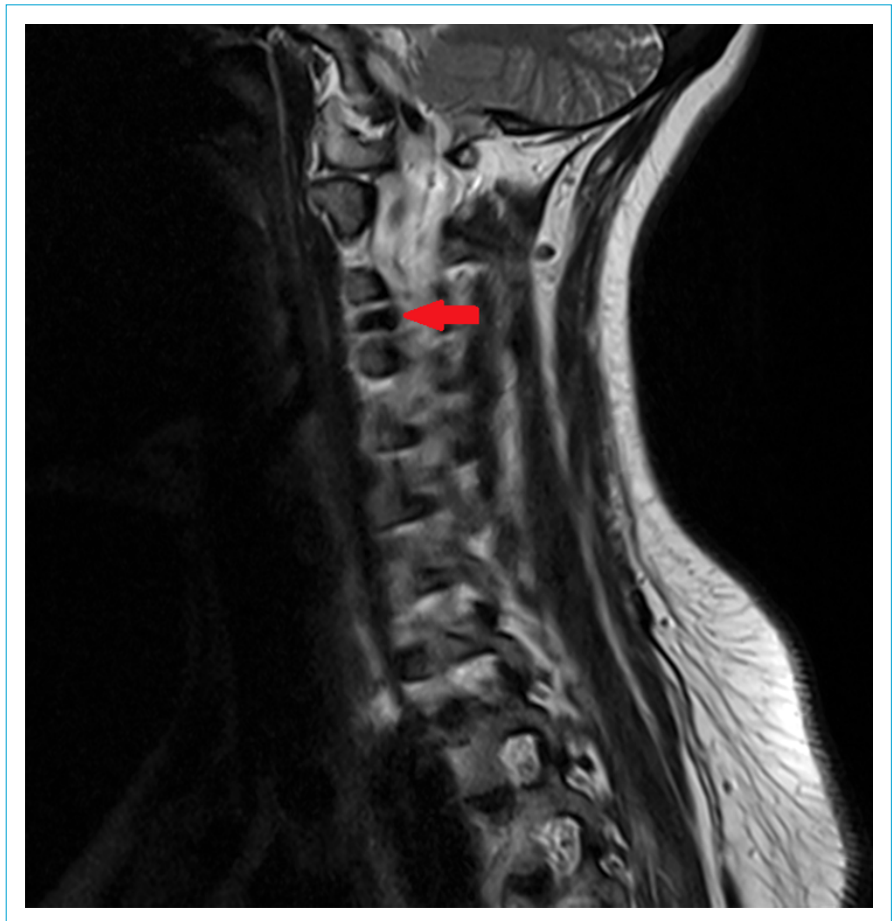

Figure 2. T2 AS, MR image at the sagittal plane, vascular structure with characteristic "signal void" appearance (red arrowhead) occupying neural foramen at the C2-3 level.

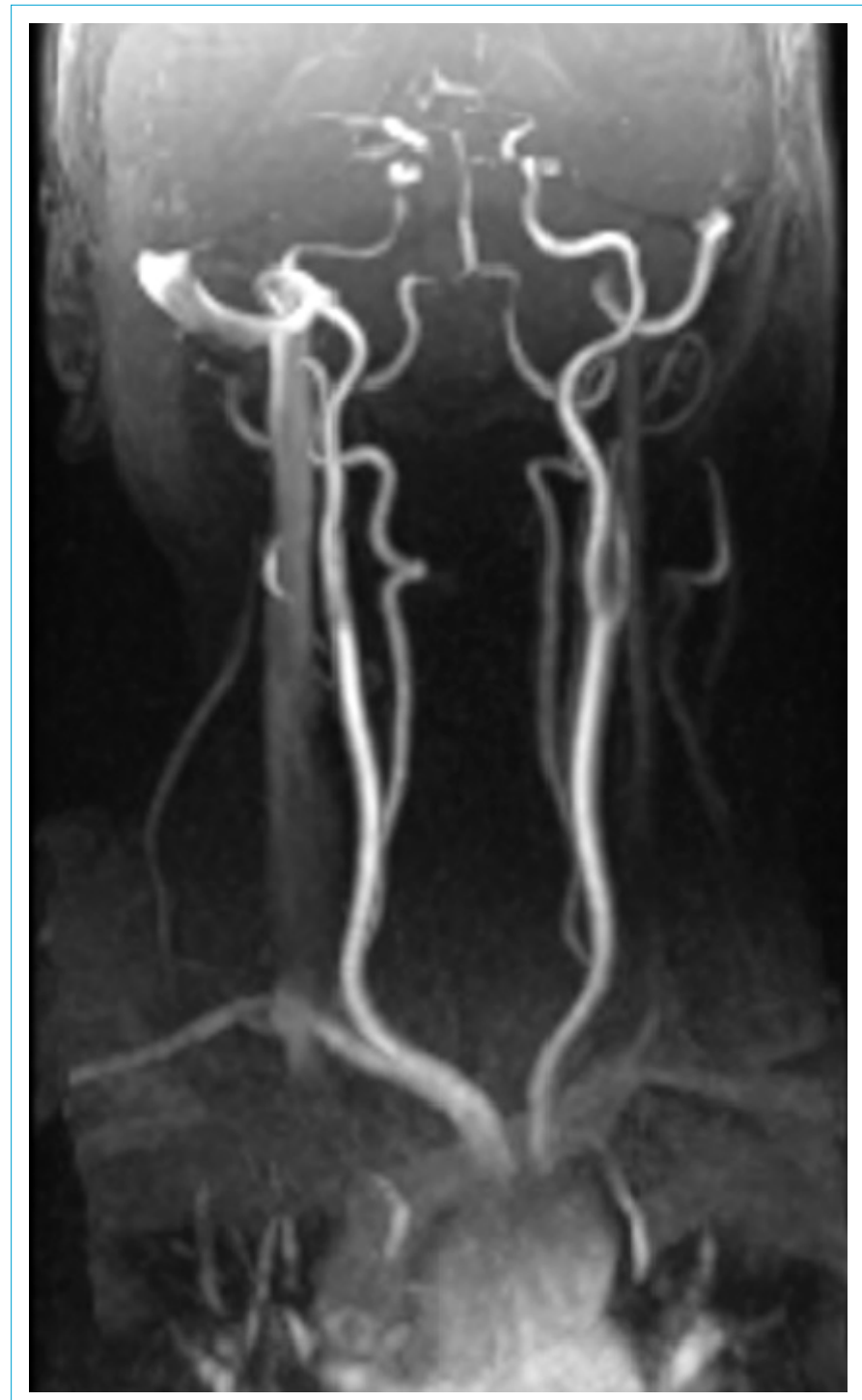

Figure 3. Loop formation observed at right VAV2 segment in contrast-enhanced magnetic resonance angiography examination.

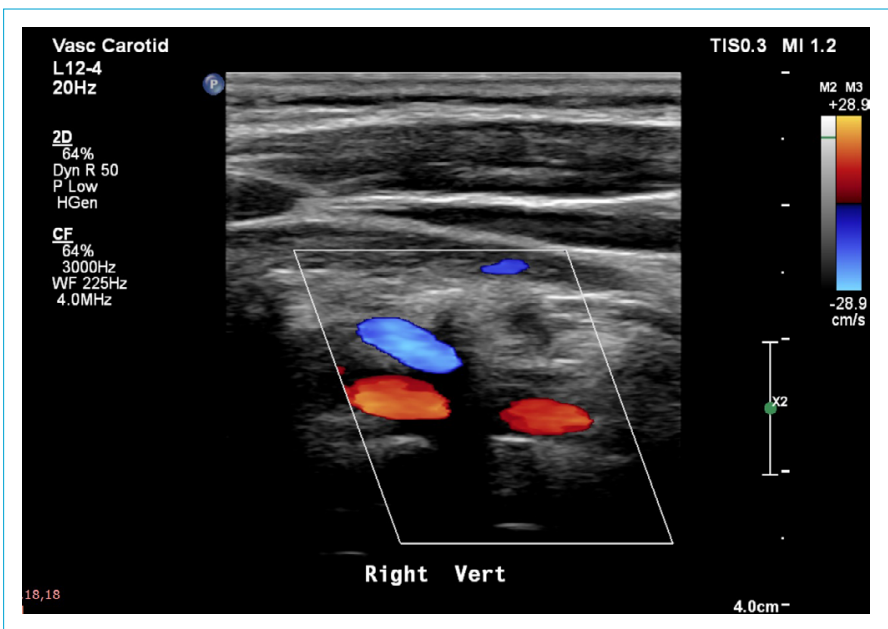

Figure 4. Right VAV2 segment with normal flow pattern on Radius Health strikes examination. 


\section{Discussion}

VA loop is a rare condition that may cause cervical radiculopathy and vertebrobasilar insufficiency. It is seen in equal incidence rates in both sexes. This variation, which occurs due to congenital or acquired causes, is usually diagnosed incidentally during examinations performed for cervical pain or cervicooccipital neuralgia. ${ }^{[3]}$ Symptoms very rarely manifest due to indentation of the convoluted structure of $V A$ at the level of the neural foramen and its compression on nerve roots in this region. ${ }^{[4,5]}$ Large cervical neural foramen makes it possible to visualize vascular anomalies such as aneurysm, arteriovenous malformation, and neoplastic processes in this area by MR or computed tomography. ${ }^{[6]}$ Although these lesions are rarely seen entities, it should be remembered that it may cause myelopathy, radiculopathy, and intervertebral foramen stenosis and they should be kept in mind in the differential diagnosis. ${ }^{[7-9]}$ This very rarely symptomatic variations can erode vertebral foramen as well as directly suppress the cervical nerve root at the level of its origin..$^{[5,10,11]}$ Depending on the level of variation in VA, different symptoms occur. Symptoms such as glossopharyngeal neuralgia, spasmodic torticollis, occipital neuralgia, Horner's syndrome, dysphagia, mass sensation in the pharynx, and neurogenic hypertension appear at high -level variations. At lower levels, symptoms of cervicobrachial neuralgia such as paresis and dysesthesia are seen in the hands without any triggering factor. Very rarely, neurological symptoms may be part of the clinical picture. ${ }^{[12]} \mathrm{MRI}$ is an effective diagnostic tool for detecting vascular variations. Specifically, the cervical neural foraminal area is clearly visualized using T1 and T2 AS (weighted sequence). Due to the "signal void" characteristics of the fluid in the vein, the tracings of the vascular structures are easily determined. In addition, three-dimensional time of flight MR angiography technique clearly shows the vascular tract. In this way, the relationship between VA and nerve root is monitored in a multiplanar setting. It is possible to determine surgical treatment strategies such as laminectomy or foraminectomy after this imaging procedure. Depending on the convoluted vertebral artery, nerve compression in the neural foraminal area is likely. In our case, vascular compression findings due to VA loop in C3 nerve root are demonstrated RDUS (color Doppler ultrasonography) data, which is evaluated as normal in addition to the existing MR images.

\section{Conclusion}

Symptoms of the cervical region, and the upper extremity of the cervical region developed due to vertebral artery variations, and related cases are rarely reported in litera- ture. In this group of patients that are rarely encountered in the population irrespective of age, and gender, symptoms of cervical nerve compression often lead a progressive course. Radiological imaging modalities for these symptoms, which are generally expected to be secondary to cervical discopathy, are effective methods for revealing rare pathologies, especially vascular variations, and they are also of particular importance for the treatment process.

\section{Disclosures}

Peer-review: Externally peer-reviewed.

Conflict of Interest: None declared.

\section{References}

1. Williams $P L$, Warwick $R$, Dyson $M$, Bannister $L H$, Ellis $H$, editors. Gray's Anatomy. 37th ed. Edinburgh: Churchill Livingstone; 1989. p. 318.

2. Taitz C, Nathan H, Arensburg B. Anatomical observations of the foramina transversaria. J Neurol Neurosurg Psychiatry 1978;41:170-6. [CrossRef]

3. Paksoy Y, Levendoglu FD, Ogün CO, Ustün ME, Ogün TC. Vertebral artery loop formation: a frequent cause of cervicobrachial pain. Spine (Phila Pa 1976) 2003 ;28:1183-8. [CrossRef]

4. Freilich M, Virapongse C, Kier EL, Sarwar M, Bhimani S. Foramen transversarium enlargement due to tortuosity of the vertebral artery. Computed tomographic appearance. Spine (Phila Pa 1976) 1986;11:95-8. [CrossRef]

5. Hyyppä SE, Laasonen EM, Halonen V. Erosion of cervical vertebrae caused by elongated and tortuousvertebral arteries. Neuroradiology 1974;7:49-51. [CrossRef]

6. Decker RE, San Augustin W, Epstein JA. Spinal epidural venous angioma causing foraminal enlargementand erosion of vertebral body. Case report. J Neurosurg 1978;49:605-6. [CrossRef]

7. Detwiler K, Godersky JC, Gentry L. Pseudoaneurysm of the extracranial vertebral artery. Case report. J Neurosurg 1987;67:935-9.

8. Kikuchi K, Kowada M. Nontraumatic extracranial aneurysm of the vertebral artery. Surg Neurol 1983;19:425-7. [CrossRef]

9. Rahimizadeh A, Sabouri-Daylami M, Amir-Moezi N, Haddadian K. Traumatic aneurysm of the extracranial vertebral artery. Neurosurgery 1986;19:628-30. [CrossRef]

10. Dory MA. CT demonstration of cervical vertebral erosion by tortuousvertebral artery. AJNR Am J Neuroradiol 1985;6:641-2.

11. Schima W, Stiglbauer R, Trattnig S, Heimberger K, Kramer J, Imhof $\mathrm{H}$. Case report: cervical intervertebral foramen widening caused byvertebral artery tortuosity--diagnosis with MR and colourcoded Doppler sonography. Br J Radiol 1993;66:165-7. [CrossRef]

12. Gatti JM, Juan LH, Bironne P, Glowinski J. Widening of a cervical intervertebral foramen by a vertebralmegadolichoartery. [Article in French]. Presse Med 1983;12:2056. 